\title{
Quality of Life Profile Based on Controlled First-line Antiretroviral Treatment in Patients with HIV Infection
}

\author{
Setiyo Budi Santoso ${ }^{1}$, Heni Lutfiyati ${ }^{2}$, Ulfahishofi Hanifah Afifi ${ }^{3}$, Shellyta Ratnafuri ${ }^{4}$ \\ $\left\{\right.$ sb@unimma.ac.id $\left.{ }^{1}\right\}$ \\ Department of Community and Clinical Pharmacy, Faculty of Health Science, Universitas \\ Muhammadiyah Magelang ${ }^{1,2}$ \\ KRT Setjonegoro Regional Public Hospital, Wonosobo, Indonesia ${ }^{3,4}$
}

\begin{abstract}
Many publications have explored the various aspects of the patients with HIV characteristics associated with quality of life. Our study aims to present data on the quality of life of HIV patients based on the combination antiretroviral treatment they are currently undergoing. This research is the result of observations at KRT Setjonegoro Regional Public Hospital, Wonosobo, Indonesia. The assessment used the Indonesian version of the WHOQOL-HIV Bref instrument. Retrieval of study data included 63 ambulatory patients with HIV taking controlled first-line antiretrovirals. To improve QoL scores, practitioners need to focus on specific interventions based on combination antiretroviral regimens.
\end{abstract}

Keywords: WHOQOL-HIV Bref, Ambulatory Patients, Hospital

\section{Introduction}

Quality of life (QoL) assessment in patients with HIV initially focused on improving conditions prone to isolation and stigma [1]-[3]. Furthermore, the QoL approach developed as an approach to make HIV patients happy and prosperous, such as the elderly [4], low income [4]-[6], unemployment, to people who do not have a spouse [5], [6].

Previous publications have highlighted the QoL gender-based for patients with HIV. Women need to get support from health workers [7]. Practitioners who manage them have also received recommendations to pay attention to groups' psychosocial aspects with alcohol disorders [8]. Various publications have even highlighted the importance of health workers managing the welfare of those who have not been able to achieve optimal CD4 cell counts [9][11].

Furthermore, previous researchers have suggested that a standard happiness intervention is a strategic measure to increase QoL [12]. Technically, providing easy access to therapy is undoubtedly a welfare privilege for HIV patients [13], [14]. The issue of therapy adherence is closely related to a good QoL score [9], [13], [14].

We are raising an issue that previous researchers have rarely studied. As short as we have reviewed, it is not easy to find a publication that provides a quality-of-life profile based on the antiretroviral regimen. This paper wanted to pinpoint the weak points of quality of life in our study subjects with various variants of the combination antiretroviral they were undergoing. 


\section{Method}

All research protocols have received approval from the Faculty of Medicine's Ethics Committee, Gadjah Mada University (KE/FK/0217/ EC/2019). The research took place at the KRT Setjonegoro Hospital in March-April 2019. Data collection was carried out by crosssectional observation. We have obtained a sample size using non-probability sampling. All subjects involved in this study were ambulatory patients with HIV taking controlled antiretrovirals for at least six months. We limited the involvement of participants who were 15 years of age and on first-line antiretroviral therapy. We ensured that all study subjects had signed informed consent that they understood. Measurement of quality of life used the Indonesian version of the WHOQOL-HIV BREF instrument [22]. The research results are presented descriptively by cross tabulating with SPSS.

\section{Results and Discussion}

\subsection{Results}

We have balanced the proportion of our study subjects' characteristics based on gender (male; $51.5 \%$ ) along with people with a spouse or single (50\%). Based on age, the majority were in the range of 20-39 years $(80 \%)$. Half of the research subjects had taken the secondary level of education $(50 \%)$ show in Figure 1.

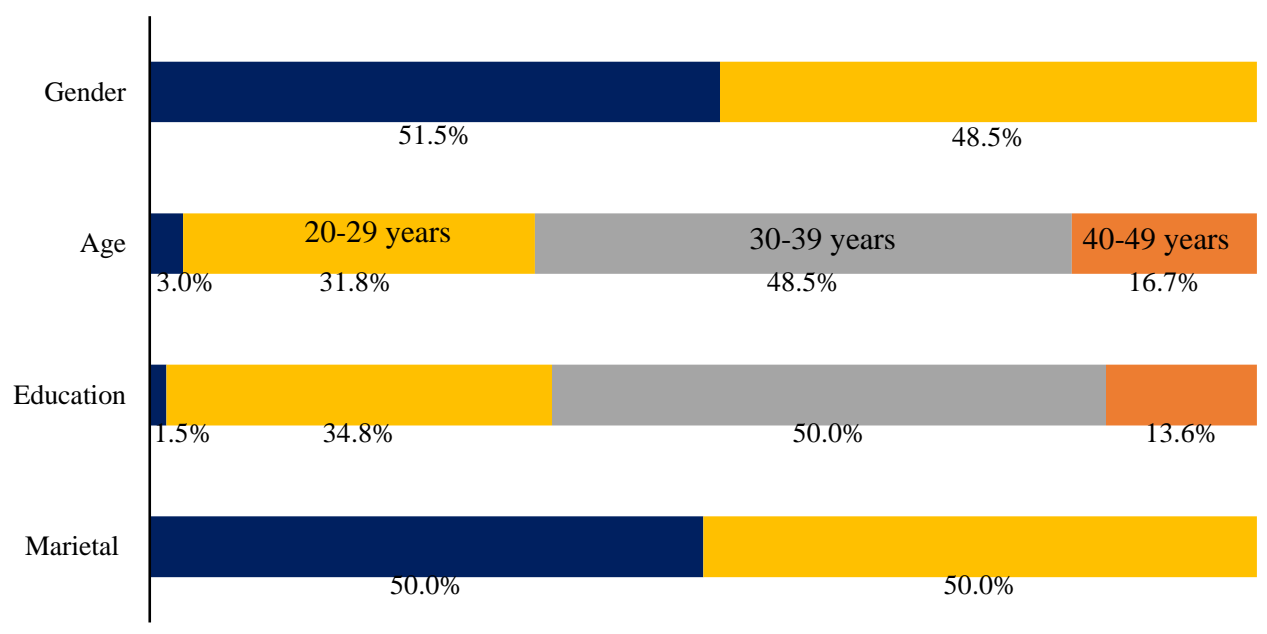

Fig. 1. The proportion of the characteristics of research subjects involved in the study

The average value of the quality of life of the research subjects is as listed in Figure 2. The highest average score is the social relationship domain (15.45). The lowest mean score is the domain environment (14.43). 


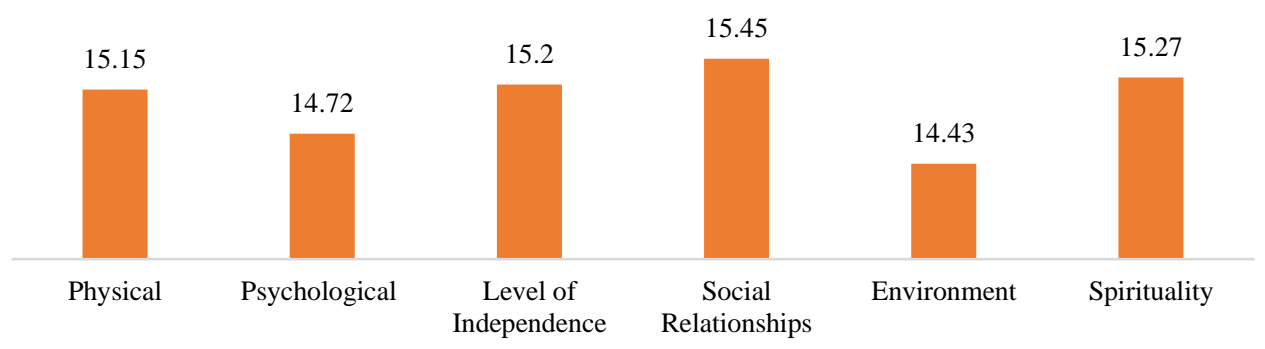

Fig. 2. Mean QoL scores in study subjects and other populations from various publications

We have highlighted several weak points of our subjects' quality of life (figure 3). The presenting data are profile values below the average for each part (see figure 2). Patients with zidovudine-lamivudine-efavirenz seemed to suffer more in aspects of physical (14.8), psychological (13.6), social relationships (14.6), and environment (13.6). Patients with Tenofovir-Lamivudine-Efavirenz had a poor quality of life on physical aspects (14.79), level of independence (14.79), and spirituality (14.29). Patients with Tenofovir-Emricitabin-Efavirenz were weak in physical quality (14.67), psychological (13.6), level of independence (15), and spirituality (14). Patients with zidovudine-lamivudine-nevirapine suffered at the level of independence $(14,88)$ and social relationships $(14,92)$.

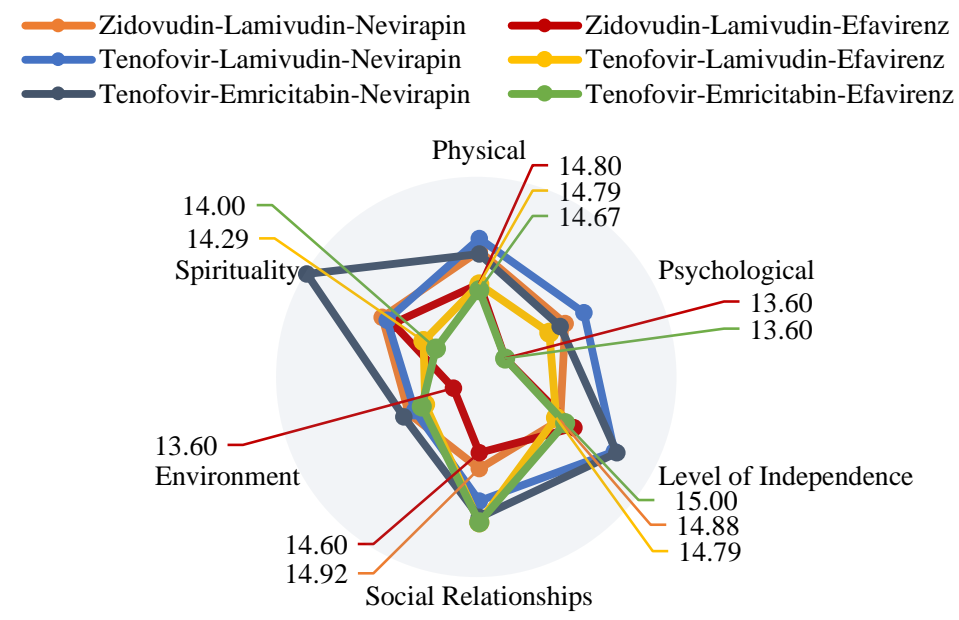

Fig. 3. Quality of Life Profiles Based on Controlled Treatment-Naive Patients with HIV Infection

\subsection{Discussion}

QoL assessment is an alternative clinical outcome parameter for chronic, even barely curable disease, especially in patients prone to stigmatization [23]. For practitioners, QoL assessment is an essential source of information for evaluating their services [24]. It forms the basis of interventions to improve the well-being, social functional status, and environment of 
HIV patients [25]. This study is our effort to continue the consistency of research on the scope of quality of life and the perspective of people taking medicines [26]- [28].

The WHOQOL-HIV Bref instrument used in the measurement was applicable to evaluate physical, psychological, social, and spiritual [18], [29]. Many investigators in various countries have published the results of testing the validity and reliability of WHOQOL-HIV Bref with various characteristics of patients with HIV [15], [18], [22], [25], [29].

Previous publications have clearly stated that ease of patient access to antiretrovirals is an enhancer of the patients' QoL [13]. This ease of access leads to high adherence to therapy [9], [11], [13]. However, a good QoL, such as adequate self-confidence and spirituality, is the basis for patients to continue therapy [10], [20].

Our previous report showed that antiretroviral treatment in HIV patients complied with national guidelines [30], [31]. The primary choice of antiretroviral combinations is Tenofovir/Lamivudine (or Emricitabine)/Efavirenz. The Tenofovir/Lamivudine/Efavirenz combination preparations are available in fixed-dose combinations. The group of patients with chronic diabetes, uncontrolled hypertension, and renal failure (creatinine clearance $<50 \mathrm{ml} / \mathrm{min}$ ) should avoid tenofovir. Patients with hemoglobin levels $<10 \mathrm{~g} / \mathrm{dL}$ were unable to start zidovudine therapy [31].

Quality of life cross tabulation based on antiretroviral combinations is an uncommon topic. These results can predict practitioners' efforts to improve aspects of the patient's quality of life. Unfortunately, we can only present quantitative data with limited sample size. Even so, we invite further researchers to investigate further with a larger population. Neither is the exploration of causality qualitatively. We hope that the effect of quality-of-life scores based on combination therapy has an adequate explanation. It is appropriate that we have studied the potential for interactions using several drug combinations. The effect of drug interactions on quality of life is also an exciting theme for further study.

\section{Conclusion}

Practitioners need to take the physical, psychological, social, and environmental aspects of patients who undergo zidovudine-lamivudine and efavirenz. In comparison, patients with zidovudine-lamivudine-nevirapine management should focus on the level of independence and social relationships. Patients with Tenofovir-Lamivudine-Efavirenz need to receive special treatment on physical, level of independence, and spirituality. Finally, in patients with Tenofovir-Emricitabin-Efavirenz, they needed to have physical, psychological, level of independence, and spirituality improvements.

\section{References}

[1] R. K. Reis, C. B. Santos, and E. Gir, 'Quality of life among Brazilian women living with HIV/AIDS', AIDS Care, vol. 24, no. 5, p. 10, 2012.

[2] A. Tesfay, A. Gebremariam, M. Gerbaba, and H. Abrha, 'Gender Differences in Health-Related Quality of Life among People Living with HIV on Highly Active Antiretroviral Therapy in Mekelle Town, Northern Ethiopia', BioMed Res. Int., vol. 2015, pp. 1-9, 2015, doi: 10.1155/2015/516369.

[3] J. H. Cronje, M. Williams, L. Steenkamp, D. Venter, and D. Elkonin, 'The quality of life of HIVinfected South African university students: Experiences with the WHOQOL-HIV-Bref', AIDS Care, vol. 29, no. 5, pp. 632-635, May 2017, doi: 10.1080/09540121.2016.1234688. 
[4] Y. Yang, S. Thai, and J. Choi, 'An evaluation of quality of life among Cambodian adults living with HIV/AIDS and using antiretroviral therapy: a short report', AIDS Care, vol. 28, no. 12, pp. 15461550, Dec. 2016, doi: 10.1080/09540121.2016.1192100.

[5] Z. Ming et al., 'Two-Year Prospective Cohort Study on Quality-of-Life Outcomes Among People Living With HIV After Initiation of Antiretroviral Therapy in Guangxi, China', J. Assoc. Nurses AIDS Care, vol. 25, no. 6, pp. 603-613, Nov. 2014, doi: 10.1016/j.jana.2014.04.003.

[6] N. Nobre, M. Pereira, R. P. Roine, H. Sintonen, and J. Sutinen, 'Factors associated with the quality of life of people living with HIV in Finland', AIDS Care, vol. 29, no. 8, pp. 1074-1078, Aug. 2017, doi: 10.1080/09540121.2017.1281879.

[7] B. X. Tran et al., 'Gender differences in quality-of-life outcomes of HIV/AIDS treatment in the latent feminization of HIV epidemics in Vietnam', AIDS Care, vol. 24, no. 10, pp. 1187-1196, Oct. 2012, doi: 10.1080/09540121.2012.658752.

[8] B. X. Tran, L. T. Nguyen, C. D. Do, Q. L. Nguyen, and R. M. Maher, 'Associations between alcohol use disorders and adherence to antiretroviral treatment and quality of life amongst people living with HIV/AIDS', BMC Public Health, vol. 14, no. 1, p. 27, Dec. 2014, doi: 10.1186/1471-2458-14-27.

[9] M. Liping, X. Peng, L. Haijiang, J. Lahong, and L. Fan, 'Quality of Life of People Living with HIV/AIDS: A Cross-Sectional Study in Zhejiang Province, China', PLOS ONE, p. 14, 2015.

[10] Y. S. Handajani, Z. Djoerban, and H. Irawan, 'Quality of Life People Living with HIV/AIDS: Outpatient in Kramat 128 Hospital Jakarta', Acta Med Indones, vol. 44, no. 4, p. 7, 2012.

[11] E. Karkashadze, M. A. Gates, N. Chkhartishvili, J. DeHovitz, and T. Tsertsvadze, 'Assessment of quality of life in people living with HIV in Georgia', Int. J. STD AIDS, vol. 28, no. 7, p. 7, 2017.

[12] N. Khademi, S. Saeidi, A. Zangeneh, F. Saeidi, and M. Choobtashani, 'The Relationship between Life Satisfaction and Quality of Life among People Living with HIV/AIDS in Kermanshah-West of Iran', Health Soc. Care Community, p. 7, 2020.

[13] A. Suswani, A. A. Arsin, R. Amiruddin, M. Syafar, and S. Palutturi, 'Factors related quality of life among people living with HIV and AIDS in Bulukumba', Int. J. Community Med. Public Health, vol. 5 , no. 8 , p. $5,2018$.

[14] M. Zhao, 'Factors associated with hostility among people living with HIV/AIDS in Northeast China: a cross-sectional study', BMC Public Health, vol. 19, no. 1189, p. 10, 2019.

[15] N. Meemon, S. C. Paek, D. Yenchai, and T. T. H. Wan, 'Application of the WHOQOL-HIV-BREF Questionnaire in HIV-Infected Thai Patients: Reliability and Validity of the Instrument', J. Assoc. Nurses AIDS Care, vol. 27, no. 5, pp. 698-708, Sep. 2016, doi: 10.1016/j.jana.2016.04.007.

[16] A. C. Ferreira, A. L. Teixeira, M. F. Silveira, and M. Carneiro, 'Quality of life predictors for people living with HIV/AIDS in an impoverished region of Brazil', Rev. Soc. Bras. Med. Trop., vol. 51, no. 6, pp. 743-751, Dec. 2018, doi: 10.1590/0037-8682-0442-2017.

[17] F. B. M. Oliveira and M. E. B. Moura, 'Quality of life and associated factors in people living with HIV/AIDS', Acta Paul. Enferm., vol. 28, no. 6, p. 7, 2015.

[18] Y. Zhu, J. Liu, and B. Qu, 'Psychometric properties of the Chinese version of the WHOQOL-HIV BREF to assess quality of life among people living with HIV/AIDS: a cross-sectional study', BMJ Open, vol. 7, no. 8, p. e016382, Aug. 2017, doi: 10.1136/bmjopen-2017-016382.

[19] J. da Silva, K. Bunn, R. F. Bertoni, O. A. Neves, and J. Traebert, 'Quality of life of people living with HIV', AIDS Care, vol. 25, no. 1, pp. 71-76, Jan. 2013, doi: 10.1080/09540121.2012.686594.

[20] C. Zubaran et al., 'Quality of life and adherence to antiretroviral therapy in Southern Brazil', AIDS Care, vol. 26, no. 5, pp. 619-625, May 2014, doi: 10.1080/09540121.2013.841838.

[21] S. Handayani, N. Y. Ratnasari, P. H. Husna, M., and T. Susanto, 'Quality of Life People Living with HIV/AIDS and Its Characteristic from a VCT Centre in Indonesia', Ethiop. J. Health Sci., vol. 29, no. 6, 2019, doi: 10.4314/ejhs. v29i6.13.

[22] N. N. Muhammad, H. Shatri, Z. Djoerban, and M. Abdullah, 'Uji Kesahihan dan Keandalan Kuesioner World Health Organization Quality of Life-HIV Bref dalam Bahasa Indonesia untuk Mengukur Kualitas Hidup Pasien HIV/AIDS', J. Penyakit Dalam Indones., vol. 4, no. 3, p. 112, Sep. 2017, doi: 10.7454/jpdi. v4i3.137. 
[23] J. Gaspar, R. K. Reis, F. M. V. Pereira, L. A. de S. Neves, C. de C. Castrighini, and E. Gir, 'Quality of Life in Women with Hiv/Aids in a Municipality in the State of são Paulo', Rev. Esc. Enferm. USP, vol. 45, no. 1, pp. 230-236, Mar. 2011, doi: 10.1590/S0080-62342011000100032.

[24] B. X. Tran, 'Quality of Life Outcomes of Antiretroviral Treatment for HIV/AIDS Patients in Vietnam', PLoS ONE, vol. 7, no. 7, p. 8, 2012.

[25] M. Salehi, S. Niroumand, M. Erfanian, R. Sajjadi, and M. Dadgarmoghaddam, 'Validation of Persian version of WHOQOL-HIV BREF questionnaire in Islamic Republic of Iran', East. Mediterr. Health J., vol. 22, no. 9, pp. 647-653, Sep. 2016, doi: 10.26719/2016.22.9.647.

[26] S. B. Santoso, D. A. Perwitasari, I. N. Faridah, and A. A. Kaptein, 'Hubungan Kualitas Hidup Dan Persepsi Pasien Tentang Penyakit Diabetes Mellitus Tipe 2 Dengan Komplikasi', Pharmaciana, vol. 7, no. 1, p. 33, 2017, doi: 10.12928/pharmaciana. v7i1.4699.

[27] D. A. Perwitasari, S. B. Santosa, I. N. Faridah, and A. A. Kaptein, 'Illness Perceptions and Quality of Life in Patients with Diabetes Mellitus Type 2', Indones. J. Clin. Pharm., vol. 6, no. 3, pp. 190199, 2017, doi: 10.15416/ijcp.2017.6.3.190.

[28] S. B. Santoso, H. Lutfiyati, R. I. Prasidha, S. Ratnafuri, and K. A. Azzahra, 'What do patients with HIV-infection perceive and know regarding to antiretrovirals? An exploration among participants undergoing controlled-therapy', Technol. Rep. Kansai Univ., vol. 62, no. 04, p. 7, 2020.

[29] P.-C. Hsiung et al., 'Validation of the WHOQOL-HIV BREF among HIV-infected patients in Taiwan', AIDS Care, vol. 23, no. 8, pp. 1035-1042, Aug. 2011, doi: 10.1080/09540121.2010.543881.

[30] H. Lutfiyati, S. B. Santoso, P. Pribadi, and S. Ratnafuri, 'The use of antiretroviral therapy (ARV) in HIV/AIDS patients', Technol. Rep. Kansai Univ., vol. 62, no. 03, p. 6, 2020.

[31] Peraturan Menteri Kesehatan Republik Indonesia Nomor 87 Tahun 2014 Tentang Pedoman Pengobatan Antiretroviral. 2014. 